\title{
Self-Organizing: \\ From Child's Play to An Effective Wellness Program
}

\author{
Francisco Guajardo \\ Department of Educational Leadership, University of Texas Pan-American \\ 1201 West University Drive, Edinburg, Texas, 78539, United States \\ Tel: 1-956-665-2945 E-mail: guajardo@utpa.edu \\ Brian Warren \\ Department of Communications, University of Texas Pan-American \\ 1201 West University Drive, Edinburg, Texas, 78539, United States \\ Tel: 1-956-665-7474 E-mail: bjwarren@utpa.edu \\ Lin Wang (Corresponding author) \\ Department of Health \& Kinesiology, University of Texas Pan-American \\ 1201 West University Drive, Edinburg, Texas, 78539, United States \\ Tel: 1-956-665-2311 E-mail: wangl@utpa.edu
}

Received: 27-02- 2013

doi:10.7575/aiac.ijkss.v.1n.1p.16
Accepted: 05-04- 2013

Published: 30-04- 2013

\begin{abstract}
This article examines the exercise practices of a group of faculty members at a regional university who for a decade have participated in their own racquetball league. These professors self-organized their exercise regimen and during the period of their participation have found significant benefits beyond the physical benefits, as a result. Through the production of reflective narratives focused on the impact of their racquetball participation, their self-reported data show two broad themes and numerous sub-themes that emerge from their exercise experience. They reveal significant health benefits, and they express more deeply the benefits of the positive social interaction that impacts many aspects of their personal and professional lives. The self-reported data from six players was requested and collected during a 6-week period. Faculty members were asked to write freely on the self-organizational aspects of their racquetball participation as well as their perceived benefits of this particular exercise. A qualitative textual analysis was applied to these narratives after they were coded for anonymity. Subsequent conclusions were drawn from the analyses of the content of each narrative.
\end{abstract}

Keywords: exercise, self-organizing, social interaction, health benefits

\section{Introduction}

Commentary on American physical health reveals increased concerns of a steady overall decline. First Lady Michelle Obama, for example, has committed herself to leading a national campaign (called "Let's Move") on health and fitness: "We now spend nearly $\$ 150$ billion a year to treat obesity-related health conditions like cancer, heart disease, and diabetes... we must combat the obesity epidemic (Obama, 2012). As Obama and others have pointed out repeatedly, at the top of reasons for health concerns is physical inactivity (Sigerist, 1996).

Humans have innate needs to be physically active; indeed, throughout our long history we have mostly depended on our cardiovascular and muscular systems, almost as much as our brains, to achieve our goals (Doherty 1976). However, this innate physicality has been slowly compromised by the kinds of jobs worked by many Americans - our inaction stems in part from sedentary employment environments (Blair, 2009). As Gardner (2011) states, "Staring at the computer for hours rather than hoeing the fields means Americans are burning hundreds fewer calories a day than they did 50 years ago" (p. 75).

How, then, can we promote wellness in work places and institutions where lack of inherent physical activity is the norm (Marshall, 2004)? Even educational institutions, many of which feature excellent exercise facilities for faculty, staff, and students, suffer from the same decline in employee health. As an example, a regional public university reported in 2004 that the average weight of both men and women was higher than it should have been according to the National Health \& Nutrition Examination Survey (Provost's Initiative on Campus Wellness). Employees revealed a decided lack of initiative in starting a wellness or fitness routine.

Motivation to exercise at all, therefore, is certainly a key factor. This article describes how wellness programs could improve if they operated from the standpoint of employee motivation, particularly if institutions listened carefully to what motivates employee interest in exercise. Comprehensive and effective wellness programs must at least consider the sports and fitness areas that the school employees themselves gravitate toward. 
People choose sports activities for at least two reasons: fun and competition. The former is crucial, according to Lauve Metcalfe of the Campbell Institute for Health and Fitness (Tkac, 1988). Competition can build self-confidence, selfrespect, and the impetus to improve. These factors together are catalysts for participation in any exercise or sport program, and a wellness program could benefit by their inclusion. As this article contends, participants themselves possess awareness of their own motivation, so a self-organized approach from participants may offer the best solution for keeping employees active with long-term exercise programs at institutions.

When faculty members are engaged in fitness programs, the research literature reveals that fitness helps overall job performance (Alegria, 2009; Neck \& Cooper, 2000). Faculty and staff members represent a source of human capital and demand sustainable development by obtaining sustainable health. Physically and mentally healthy faculty members can create more economic value by being more productive with scholarly work. At the same time, as in any other field of employments, faculty members who adopt risky health behaviors such as smoking, drinking, and/or a sedentary lifestyle will contribute to higher economic-cost outcomes such as medical costs (Cawley \& Ruhm, 2011).

It is the self-organized exercise behavior existing within the institution (or in the case of this article, the campus) that best promotes physical and mental health. The process of self-organizing is best understood by the observed actions and interactions of the individuals involved. Also termed autogenesis to differentiate its perspective from other models of organization, the process occurs "through self-organizing capacities of individuals interacting in a social field" (Drazen \& Sandelman, 1992, p. 231).

\section{A Faculty Member's Childhood Story}

One faculty member produced a narrative that focused on his exercise experience and offered an additional story he found pertinent, particularly as it related to the university's existing wellness program. His narrative draws an analogy between the institution's wellness program and a story from his childhood.

"I have fond memories of growing up in a rural South Texas town. I was raised with my brothers and parents in the federal housing projects and grew up closely with about a dozen other kids who lived in and around the housing projects. They were my childhood friends and the people from whom I learned the most about leadership, teamwork, organizing, organizations, and about how to have fun through the act of playing. From the time I was six to the time I entered my teenage years, my friends and I organized our own summer baseball league, fall football activity, the winter basketball games, and trompos (tops) and canicas (marbles) tournaments interspersed throughout the year. The youth who participated in this range of activities organized, implemented, and took care of the play. We talked about which kids would play on which teams; we secured hoes, shovels, hammers and nails from our parents to level off the baseball infield, mounted an old tire rim to a basketball backboard, or trimmed a grass line for a goal-line for our gridiron. We created schedules, gathered enough money to buy balls, bats, or gloves we might need for the season.

"We self-organized: our own play, our team sports activity, and our exercise. In so doing, we owned every part of the process, and enjoyed it in the deepest way possible. Kids kept doing this in my neighborhood, until the adults in the community created a city-sponsored baseball association. I remember it well; I was 13 years old when the league was inaugurated, and I played in the league for two years. But many of my friends from the housing projects did not. There were too many rules, the schedules were rigid, and kids had to show birth certificates, pay a fee, and essentially follow the guidelines designed by other people. Some kids could meet all the requirements, some could not, so the baseball league process emerged as exclusionary, rather than the inclusionary organization it purported to be. As the league moved in, the locus of control for play shifted from the kids in the neighborhood to the formal organization. Play would never be the same in my neighborhood. It ceased to be the rich organizing, team building, social experience that it was when kids were in charge. The new 'wellness program' was now governed by the league, the institution; exercise and play looked very different from then on."

\section{Theoretical Considerations}

The children in the above story organized themselves because they wanted to play, they wanted to interact with each other, and conditions were such that their play and self-organizing were nurtured rather than stunted. Like those children, the faculty members who are the subjects of this article merged both their biological, as Maturena and Varela (1980) describe in their thesis on autopoiesis, and social needs through the manifestation of self-organizing. As human interaction is a "foundation of social life," Smith and Stevens (1996) argue that self-organizing is a direct product of social activity that takes place within the life of an organization. Organizations typically respond to needs and desires of employees, or in this case of the faculty, but organizational responses tend to be guided by the values of the institution, or the corporate epistemology (Von Krogh, Roos, \& Slocum, 1994), rather than by the organic impulses of the institutions' employees. Self-organizing is a response to an institutional dynamic that juxtaposes institutional values with personal values and impulses.

This article makes use of faculty members' responses to their institution's wellness program status quo through narrative interplay (Hayles, 1995). Storytelling emerges as a critical method through which institutional decision-making is assessed and as a guide to lay out the wellness behaviors of a select group of self-organized faculty members who respond to their biological and social needs.

\section{Methodology}

Data collected for this study emerges from a series of reflections produced by faculty members who have participated in both an institutionally driven and a self-organized wellness program during the past decade. Faculty members employ a social network through which they organize racquetball games every day of the week, and tournaments occasionally. They work both within the institution's existing wellness program, but are also in tension with the wellness program. 
As such, they give nuance to the institution's program, which they describe through narrative form for this article. Through narratives, or personal stories, faculty members offer glimpses into parts of institutional life that system's theory may not be able to see - and to which the institution itself is often blind (Hayles, 1995). In this context, storytelling is viewed as a weighty proposition, as well as a viable methodological tool, as stories are used as reflections of how agents/employees impact institutional change (Guajardo \& Guajardo, 2010). Through the stories, which constitute the critical data set for this article, faculty members describe their experiences within this wellness program.

Participants responded to questions such as the following:

*How does the university's existing wellness program affect your exercise activity?

*Is the university's program suited to the needs of its faculty and staff?

*What are the benefits and costs of your participation in exercise activity?

Through qualitative textual analysis the authors glean from the data two broad themes that emerge as benefits of the exercise activity: physical health benefits and social interaction benefits. The data push the analysis by suggesting a number of sub-themes that emanate from physical health and social interaction. Textual analysis helps identify patterns and salient lessons for the purpose of making sense of the individual and collective reflections.

The storytelling quality of the data offers enhanced opportunities through which to view this dynamic wellness program that is both institutional and organic. Probing the data through textual analysis shows lessons that can be useful to understanding the benefits of institutional wellness programs that are sensitive to the needs of its employees. A critical function of this methodological approach is to respect the voices of participants, to honor the stories. As such, voices of participants emerge as a highly nuanced data set.

\section{Data}

The self-organized racquetball group is a small core when compared to the entire faculty of the institution. All participants are male, tenured or tenure-track university faculty. They are self-motivated in regard to physical health and wellness and can be described as veterans of the racquetball culture in that they all have played for three years or more, in some cases much longer. Without question, all participants could be considered productive faculty within each person's own discipline and by the common university standards of teaching effectiveness, scholarly achievement, and service to the community. The participants in the study are a random sampling of the faculty racquetball players in that the call for submissions was generated to the entire group in the initial two-week period of inquiry.

This article addresses the exercise activities of selected faculty members at a regional public university who have selforganized a racquetball-playing group. The written narratives concerning their experiences were collected and their unedited content dissected. When asked to narrate their stories regarding the racquetball-playing group, all expressed profound benefits in two major areas: health benefits and social interaction. The sub-themes included enhanced physical and mental health, development of richer friendships and relationships, collegiality, collaborative partnerships, development of networks. The impact of the themes and sub-themes manifest themselves through increased personal and professional productivity. Each participant is labeled with a random designation, from P1 to P6 (p=participant).

Table 1. Participant Data Chart

\begin{tabular}{|c|c|c|c|}
\hline Indicators & Sub-themes & Themes & Lessons \\
\hline $\begin{array}{l}\text { P1 "My stress level has been greatly in check, as } \\
\text { proven by my annual physical checkup. My blood } \\
\text { pressure is around } 130 \text { over } 80 \ldots \text {... }\end{array}$ & Physical health & $\begin{array}{l}\text { Individual } \\
\text { Health } \\
\text { Benefits }\end{array}$ & $\begin{array}{l}\text { Productivity\& } \\
\text { Institutional } \\
\text { Enhancement }\end{array}$ \\
\hline $\begin{array}{l}\text { "A cardiologist who recently performed my annual } \\
\text { physical exam was amazed at the vital signs..." } \\
\text { P2 "During the entire time that I have been at this } \\
\text { university [over } 30 \text { years], I have probably had a total }\end{array}$ & & & $\begin{array}{l}\text { 1. racquetball enhances } \\
\text { physical, social, } \\
\text { professional strength }\end{array}$ \\
\hline $\begin{array}{l}\text { of only four or five days of sickness that prevented me } \\
\text { from coming to work." }\end{array}$ & & & $\begin{array}{l}\text { 2. relationships } \\
\text { strengthened through }\end{array}$ \\
\hline "I attribute this record of good health to a regular & & & racquetball \\
\hline $\begin{array}{l}\text { fitness program, which I have found primarily in } \\
\text { racquetball." }\end{array}$ & & & $\begin{array}{l}\text { 3. institutional } \\
\text { responsiveness to }\end{array}$ \\
\hline $\begin{array}{l}\text { P3 "I am an old man...; at my age one can only } \\
\text { imagine the sorry state... if I had not played rball } \\
\text { regularly..." }\end{array}$ & & & $\begin{array}{l}\text { personal and collegial } \\
\text { exercise experience } \\
\text { important }\end{array}$ \\
\hline $\begin{array}{l}\text { "...I have been able to overcome a number of serious } \\
\text { and chronic medical conditions..." }\end{array}$ & & & \\
\hline
\end{tabular}


P4 "What matters are the healthy consequences of the exercise, and the friendships forged from the adventures on the court."

P5 "The two professors, both of whom were in their late 50 s or early $60 \mathrm{~s}$, looked very fit and very healthy. What impressed me most, however, was when one of them said that the reason he was healthy was because he had made exercise into a priority in his life. "It has to become a way of life for you," he said ..."

“...That day they became my workout partners, and more than seven years later, we have added another six or seven partners who exercise regularly, and who are among the healthiest faculty and staff members at the university..."

P6 "Racquetball has helped keep me in good shape, physically and mentally, as well as to succeed professionally"

P2 "In addition to the health benefits I have obtained from racquetball and other activities available to faculty here, I consider one of the great benefits the social capital of developing strong friendship networks with other faculty in diverse departments."

P4 "Exercise helps keep us stress-free and better able to concentrate."

P5 “...increased work productivity, and the benefits go way beyond costs in terms of improving the quality of work-life and enjoyment"

P6 "Racquetball has helped keep me in good shape, physically and mentally, as well as to succeed professionally..."

P1"Win, lose, or draw I enjoy the game, and I also enjoy kidding with my fellow players before, during, and after the games..."

P2 “...the friendships developed in a fitness program have led to other collaborative initiatives between myself and other professors."

P3 “...the other faculty members with whom I play have formed a genuine community who continue to support and encourage each other..."

P4 "I would say that a few of my better friends on the faculty are my fellow racquetball players ..."

"The enjoyment of the games is largely due to the banter and camaraderie that exists between the players, which offsets the double-digit losses I have incurred."

"Playing the games forges friendships among the faculty..."

P6 "I have found in them good friends and excellent colleagues too..."

P1 "Win, lose, or draw I enjoy the game, and I also enjoy kidding with my fellow players before, during, and after the games..."

P2 “...the friendships developed in a fitness program have led to other collaborative initiatives between myself and other professors."

P3 “...the other faculty members with whom I play have formed a genuine community who continue to support and encourage each other..."

$\begin{array}{lll}\text { Mental health } & \text { Individual } & \text { 4. institution should } \\ & \text { Health } & \text { support this activity } \\ \text { Benefits } & \text { 5. this activity enhances } \\ & \text { institutional } \\ & \text { productivity } \\ & \text { 6. activity deepens } \\ & \text { community } \\ & \text { relationships and } \\ & \text { improves morale }\end{array}$

Friendship/relat Social ionship through Interaction support and network

$\begin{array}{ll}\text { Collegiality } & \text { Social } \\ \text { relationship } & \text { Interaction }\end{array}$

through support

and network 
P4 "I have learned much about how the university works just by listening to the conversations of these players and others who work in other colleges than I do, or in administration of the university..."

P5 "The camaraderie and relationships I have built with my exercise friends has proved invaluable for me first as a junior faculty member working toward tenure, and now as an associate professor looking to earn full professorship. I have found my partners as essential for exercise purposes, but they have been equally helpful as mentors who have helped me navigate parts of academic and institutional life. Without question, I have built strong personal and professional relationships with my workout partners, but as importantly, they have taught me the critical importance of committing oneself to an exercise program..."

P6 "I have found in them good friends and excellent colleagues too. .."

"I organized the first faculty/staff racquetball social, and I helped to organize the first Ironman Racquetball Shootout tournament, an event where we hosted over 50 players who registered in divisions ranging from amateurs to professional..."

P1 "During the time I have been playing racquetball, I have published almost 100 articles, at least half of them "peer reviewed", have taught a full teaching load of graduate and undergraduate courses, and have provided consulting services to over 100 business entities..."

$\begin{array}{ll}\text { Collaborative } & \text { Social } \\ \text { partnership/sch } & \text { Interaction } \\ \text { olarship work } & \\ \text { through } & \\ \text { network } & \\ \text { Productivity } & \end{array}$

P5 "Without question, I have built strong personal and professional relationships with my workout partners, but as importantly, they have taught me the critical importance of committing oneself to an exercise program, as part of how one becomes a healthy and productive member of the faculty"

P6 "Racquetball has helped keep me in good shape, physically and mentally, as well as to succeed professionally"

Note: P1 (71 years old); P2 (68 years old); P3 (65 years old); P4 (50 years old); P5 (48 years old); P6 (42 years old)

\section{Data Analysis \& Discussion}

Effective wellness program organization and administration are complicated. The National Wellness Institute states that a culture of wellness needs to be in place before all benefits of a wellness program can be enjoyed (National Wellness Institute, 2010). As seen in Table 1, much of the narratives focus on the physical benefits of playing. The six participants comment on the general physiological benefits of any consistent exercise program and narrate this awareness as a strong motivating factor in their participation in this particular exercise group, though certainly the physical benefits were not the only, or even most important, motivating factor.

One finding shows that participants stressed the consistency of the exercise group as important to their health goals. This consistency translates to an adoption of racquetball as the main method of exercise when striving toward a healthy lifestyle. Consistent with current literature (Pajari, Jallinoja, \& Absetz, 2006; Kenkel, 2000), embracing racquetball playing and making it a way of life produces results such as positive physical exams and less reported sick leaves. A second and equally important health benefit the narratives emphasize is improved mental health. The use of terms and descriptors such as "better concentration," "decreased stress," and "relaxation," illustrate mental health benefits inherent in the racquetball group. Any institution with hard-working employees can produce at times a stressful environment, so an institutional question is often "How can we reduce stress in the workplace?" It is significant, then, to note that the narratives share a sense of enjoyment in playing the game with the consequent lessening of job-related stress.

At the same time participants in the racquetball group note their loyalty to playing results in an increased level of job productivity. Often, participants traced their increased level of productivity to the collaborative initiatives originally discussed during a racquetball session. Exercise programs during work hours are not "mini-vacations" from the job; 
they are extensions of work in that creative processes and brainstorming occur during, and are augmented by, the regular racquetball matches. People who complain that they simply do not have time to engage in regular exercise programs are ignoring documented evidence that an exercise program actually produces time (Neck \& Cooper, 2000).

All of this points toward the importance of exercise for faculty members. Whether self-organized or mandated by the university, an exercise program featuring sports or activities enjoyed by the participants is a decided benefit to the physical health, mental health, and consequent productivity levels of the participants.

Based upon literature that supports the notion that people in the United States lead physically inactive lives, the racquetball culture that exists at this university is an anomaly. The participants' introspective narratives about the selforganized physical activity resulted in a number of revelations about the nature and function of wellness programs in this university setting. Self-organized exercise behavior, especially in a group format, provides another perspective in examining different ways to implement effective wellness programs. Contemplating the suggestions from such selforganized groups devoted to physical exercise can affect the kind of institutional wellness programs in any organization. Positive wellness investment is returned if the designed program has certain characteristics as awareness, engaged leadership, identification of risk, etc. (My Wellness Choice, 2010). Most important is the kind of program offered by a university responding to interests of its employees to promote mental and physical health as well as productivity. This article describes a university's response to the "biological impulse." Testimonies from faculty members argue that very point: "There is a biological impulse to exercise, a kind of addictive feeling I get to go play racquetball, or to simply sweat," to which, a second professor responds, "My body doesn't feel right when I don't work out; I feel much better and have much better days when I do exercise." The biological impulse is a common theme in the stories written by the faculty and in the subsequent conversations they had together. The argument supporting a biological need is consistent with what Maturana and Varela (1987) describe as part of the "Tree of Knowledge." In addition to cognitive, spiritual, and emotional needs, human beings similarly respond to physiological and biological impulses. For these professors their response to a biological need is a foundational instinct, a core manifestation of their human needs.

Stories from participants also spoke to social interaction. Although exercise psychology literature points out the importance of social facilitation (Weinsburg \& Gould, 2012; Olofsson, 2010), the gap between theoretical proposal and effective implementation of wellness programs exists. Evidence on the impact that social support has on promoting physical activity were documented by Calfas, Salis, Oldenburg, and French (1997), Toobert, Glasgow, Nettekoven, and Brown (1998), as well as Steptoe, Rink, and Kerry (2000). Exercise behavior of female participants was studied in mentioned projects. Such positive influence is confirmed by the exercise stories collected from male participants in this study. Social facilitation and support should be emphasized in wellness program organization for either gender or both. The exercise stories also yield intriguing organizational behaviors, particularly in how the professors self-organize. Though their employer offers a reasonable wellness program, the professors have purposefully organized their own workout program, according to schedules and routines that are favorable to the faculty members themselves. One professor stated, "The university wellness program is a good program, but it doesn't fit most of our schedules, so every semester we organize ourselves so that all of us can exercise." The self-organizing impulse, like the biological, is driven by a "pervasive tendency," as Knowles (2002) suggests, a tendency that is found at all levels throughout nature. Listening and responding to the true impulses of wellness program participants will empower such a wellness program and its participants to answer the physiological and biological impulses and their call for the internal motivation to stay active.

It seems clear that the concept of self-organization has potentially powerful influences on institutional wellness programs. Historically, human beings have struggled against those who decide for them what is right for them. As Glasser (1998) explains in Choice Theory, how we have chosen to resist the forces of control is "by far, the greatest source of human misery" (p. 4). Faculty members, by making the independent choice to form the racquetball group, have demonstrated the wellness-producing effect of self-organization, a factor to which institutional wellness programs should pay close attention. In summary, these are the lessons learned:

1) Group racquetball (or any sport participating experience) enhances physical and mental health;

2) Personal as well as professional relationships are strengthened by participating in self-organized group racquetball;

3) Institutional responsiveness to the personal and collegial exercise experience is very important for institutional enhancement

4) Faculty members expect institutional support their self-organized exercise behavior;

5) Self-organized group exercise behavior enhances institutional productivity.

\section{Future Directions}

A theme mentioned by two different faculty members provides insight regarding possible future directions. One professor asserted and even repeated the incompatibility between the scheduled hours held by the university wellness program and the available hours when faculty members can come together to exercise. The self-organized group has consistently resisted this scheduling incongruence, and has even taken complaints about inadequate gym hours to upper administration. Another faculty member equates the university's wellness program to programs that have "too many rules" and "rigid schedules." The faculty members have worked around the inadequacies of scheduling and rule rigidity by self-organizing, both to advocate for friendlier schedules of the racquetball courts, and to ensure they have exercise partners during the university's revised schedule. Faculty members argue that if the university listens carefully to the exercise needs of its faculty, which often come through the manifestation of self-organizing, it could indeed nurture a 
wellness program responsive to the very people it purports to serve through its programming.

The lesson, then, is a basic one: listen to your employees, observe their tendencies, and respond to them-that could be an answer to improving wellness programming, and the quality of life for employees.

\section{References}

Alegria, A. (August 31, 2009). Healthier employees, both physically and mentally, benefit any company:

companies use contests and games to promote fitness. San Fernando Valley Business Journal. Retrieved from http: // http://www.sfvbj.com/

Blair, S. N. (2009). Physical Inactivity: The Biggest Public Health Problem of the 21st Century. British Journal of Sports Medicine, 43: 1-2.

Calfas, K., Sallis, J., Oldenburg, B., \& French, M. (1997). Mediators of change in physical activity following an intervention in primary care: PACE. Preventive Medicine, 26(3), 297-304.

Cawley, J. \& Ruhm, C. J. (2011). The economics of risky health behaviors, in Pauly, M. V., McGuire, T. G., \& Barros, P. P (Eds.), Handbook of Health Economics, 2, 95-199.

Drazin, R., and Sandelands, L. (1992). Autogenesis: A Perspective on the Process of Organizing. Organization Science, 3(2), pp. 230-249.

Doherty, K. (1976). Track and Field Omnibook. Los Altos, CA: Tafnews.

Gardner, A. (May 27, 2011). Sedentary Jobs Helping to Drive Obesity Epidemic. Retrieved from http://www.rxshop.md/news/7729

Glasser, W. (1998). Choice Theory: A New Psychology of Personal Freedom. New York:

HarperCollins Publishers.

Guajardo, F. and Guajardo, M. (2010). “Cultivating Stories of Change.” In Ruder, K. et al, (Eds.), Weaving Strong

Communities: The Collective Leadership Storybook. Seattle, WA: Center for Ethical Leadership.

Hayles, K. (1995). Making the Cut: The Interplay of Narrative and System, or What Systems

Theory Can't See. Cultural Critique, 30, The Politics of Systems and Environments, Part I (Spring 1995), 71-100.

Kenkel, D. S. (2000) Prevention, in Pauly, M.V., McGuire, T. G., \& Barros, P. P. (eds.), Handbook of Health

Economics, 1, $1675-1720$.

Knowles, J. (2002). The Leadership Dance: Pathways to Extraordinary Organizational Effectiveness. The Center for Self-Organizing Leadership. St. Petersburg, FL.

Marshall, A. L. (2004). Challenges and opportunities for promoting physical activity in the workplace. Journal of Science and Medicine in Sport, 7 (1): Supplement: 60-66.

Maturana, H. \& Varela, F. (1980). Autopoieses and Cognition: The Realization of the Living,

Dordrecht: Reidel.

Maturana, H. \& Varela, F. (1987). The Tree of Knowledge. Boston: Shambhala.

My Wellness Choice. (September 07, 2010). Retrieved from http://www.mywellchoiceplus.com/why-

wellness/effective-wellness-program.php

National Wellness. (September 07, 2010). Retrieved from http://www.nationalwellness.org/index.php?id_tier=1.

Neck, C. and K. Cooper. (2000). The fit executive: Exercise and diet guidelines for enhancing performance. Academy of Management Executive, 14 (2), 72-82.

Obama, Michelle (2012). The First Lady speaks out. In Vibrant Life Sep/Oct2012, Vol. 28 Issue

5, p32-33.

Olofsson, E. (2010). Wellness application: Design guidelines to encourage physical activity. In J.

B“orstler, F. Drewes, H. Gulliksson (Eds.): Ume ${ }^{\circ} a$ 's 14th Student Conference in Computing Science, USCCS 2010 , $111-125$.

Pajari, P.M., Jallinoja, P., \& Absetz, P. (2006), Negotiation over self-control and activity: An

analysis of balancing in the repertoires of Finnish healthy lifestyles. Social Science \& Medicine, 62(10), $2601-2611$.

Provost's Initiative on Campus Wellness. Unpublished internal document on a regional university's wellness. (2012).

Sigerist, H. E. (1996). Health, Journal of Public Health Policy , 17 (2), 204-234.

Smith, T. and Stevens, G. (1996). Emergence, Self-Organization, and Social Interaction: Arousal-Dependent Structure in Social Systems. Sociological Theory, 14 (2): 131-153.

Steptoe, A., Rink, E., \& Kerry, S. (2000). Psychosocial predictors of changes in physical activity in overweight sedentary adults following counseling in primary care. Preventive Medicine, 31, 183-194.

Tkac, D. (1988). Everyday Health Tips (Eds). Rodale Press, PA.

Toobert, D., Glasgow, R., Nettekoven, J., \& Brown, J. (1998). Behavioral and psychosocial

effects of intensive lifestyle management for women with coronary heart disease. Patient Education and Counseling, $35,177-188$.

Von Kroh, G., Roos, J., and Slocum, K. (1994). An Essay on Corporate Epistemology. Strategic Management Journal, 15: 53-71.

Weinsburg, R.S. \& Gould, D. (2010). Foundations of sport and exercise psychology (5th ed.), Champaign, IL: Human Kinetics. 


\section{DATA}

P1

I started playing racquetball 32 years ago, and this September will be 72 years old. I have been playing generally three times per week, averaging 12 to 18 games, or playing about 4 to 6 hours per week, since I was 48 years old. I started playing to reduce stress, have fun, and stay fit, and it has worked for me.

My stress level has been greatly in check, as proven by my annual physical check up. My blood pressure is around 130 over 80, my cholesterol is a bit high (but within normal range) and my other vital signs are mostly within normal range. After playing racquetball and showering, I feel rested and relaxed. My heartbeat during my annual physical exams is between 50 and 60 beats per minute, which is low. My doctors tell me that I must be doing effective cardiovascular exercise to have my heartbeat that low. A cardiologist who recently performed my annual physical exam was amazed at the vital signs. He does physical exams for police officers, and he told me that my vital signs were more favourable than most of his police officer patients who took physical exams with him.

I really enjoy playing racquetball! Win, lose, or draw I enjoy the game, and I also enjoy kidding with my fellow players before, during, and after the games. P2 always pushes me to keep my game sharp - one little slip and he wins the game. P5 used to have a different excuse for every game he lost, but he is getting over it. Now that wins most of the games, he does not need to make an excuse very often. His imagination for making excuses is incredible. P6 never makes excuses - he just wins games. I like to play with P3, because he is quick to apologize when he wins, even when he makes a great point. Each player is fun to play with for one reason or another.

My weight has stayed within 15 pounds of my weight when I graduated from high school. I weigh 164-168 lbs., and am 5'7" tall. I believe racquetball has increased my metabolism, and has helped me control my weight.

The biggest benefit I get from playing racquetball is undoubtedly increased productivity. During the time I have been playing racquetball, I have published almost 100 articles, at least half of them "peer reviewed", have taught a full teaching load of graduate and undergraduate courses, and have provided consulting services in the area of Marketing and Economics to over 100 business entities. I have also been active providing volunteer services to our local non-profit organizations such as chambers of commerce, public and private schools, and spiritual organizations. I have missed very few days from work.

As I see other racquetball players outside the racquetball court at restaurants, meetings, and other places I notice that they have a certain clean, clear, radiating glow. It is as if their skin is clean, and they radiate clean energy and good health. Needless to say, this is very encouraging for me.

P2

I have been playing racquetball at an American university or, more recently, at this university since I came here in 1977. In those early days, there were only three courts. It was difficult to get court time because courts had to be scheduled by walking across campus to the courts to schedule one. Often, I would find that others closer to the building had already scheduled the courts. I took a three-year leave of absence in 1985, returning in 1988. When I returned, we had the new facilities that we enjoy now and have been using them fairly regularly since that time. During this time, there have been several years when I did not continue playing because it was difficult to get courts or have a regular partner with whom to play. About 15 years ago, I found that P1 in the School of Business was a regular player and we began to play your three times a week on a regular basis.

Many years ago, I had tried several different types of exercise, including jogging, swimming, and weight training in an effort to be physically fit. I found with each of these activities it was very difficult to maintain a regular schedule because the activity became more like work, and interruptions in my workout schedule made it difficult to continue on a regular basis.

Since P1 and I began to play, we have maintained a regular schedule over the years, with few exceptions. Those exceptions came during summer vacations, spring break, and the Christmas holidays when the courts were frequently made unavailable for a variety of reasons. We have struggled during this time to use the courts on a regular basis, recognizing that breaking the regularity of our schedule could easily lead to a breakdown in our fitness program.

The most important element of a good fitness program, I have discovered, is to maintain a regular schedule in an activity that one enjoys, and in which one can find friendship as well as exercise. If racquetball, or any other physical activity, becomes more like work than play, the unavoidable interruptions inevitably lead to breaks that make it increasingly difficult to maintain the entire program.

During the entire time that I have been at this university, I have probably had a total of only four or five days of sickness that prevented me from coming to work. I attribute this record of good health to a regular fitness program, which I have found primarily in racquetball. The fact that there is a weight room close to the courts has also made it possible to add regular weight training to our fitness program. Here again, however, our workout program was interrupted when we found ourselves unable to use to use the facilities at the same time that racket courts because of scheduling problems.

In addition to the health benefits I have obtained from racquetball and other activities available to faculty at this university, I consider one of the great benefits the social capital of developing strong friendship networks with other faculty in diverse departments. One of these, for example, was the friendship developed with P3, a member of the Philosophy faculty. Because of the relationship we developed in racquetball, P3 and I developed and co-taught a course on using logic to examine current social issues. In addition, P1 and I have collaborated on at least two research projects. 
P5 and I have also worked together in several projects related to our mutual interests in the US-Mexico borderlands and education for Mexican Americans students.

On many occasions, the friendships developed in a fitness program have led to other collaborative initiatives between myself and other professors.

P3

I am an old man. I was an old man when I came to this university in 1994, and this condition has not improved in the ensuing years. Fortunately, I have been playing racquetball since 1977; at my age, one can only imagine the sorry state of my physical and mental constitutions if I had not the opportunity to play racquetball regularly with congenial companions while I have taught here. Although the colleagues with whom I play would find it difficult to believe, I am in good shape both physically and cognitively, and credit for this goes to all those at this university who take health and fitness seriously and encourage faculty to participate in appropriate activities. In addition to the normal salutary benefits that accrue from playing racquetball, I have been able to overcome a number of serious and chronic medical conditions, including a debilitating case of distal subungual onychomycosis, as a result of this valuable recreational endeavour.

Racquetball is an excellent aerobic exercise, and has been helpful in building both strength and stamina. I have not always been able to play on a regular schedule during my years here, but when I can play two-to-three times a week for a couple of hours each time over an extended period, I find that my weight stays under control, my energy level is higher, and my vital signs remain, well, vital.

But the rewards that racquetball provide are not limited to my individual well being. The other faculty and staff members with whom I play have come to form a genuine community who continue to support and encourage each other long after we have left the racquetball court. Although we have a common interest in healthful and competitive exercise, we have nurtured friendships that extend to our life together as members of an academic institution. There are a great many of my good friends whom I likely would never have known (nor worked with professionally) had I not met them on a racquetball court. In addition, I've had numerous chances to invite students to play racquetball, and in the process not only to introduce them to a fine sport, but to get to know them as persons outside the classroom.

In short, I am grateful to all those at this university who continue to provide this recreational opportunity. It has made a tremendous difference in my life as a faculty member here. As we often say, a campus without facilities and organizational opportunities for racquetball is no country for old men.

P4

My discipline within the university is theatre arts. To reach a certain level of expertise required of a faculty member, even a junior faculty member such as I am, I have had years of training as a theatre educator, but also as a playwright, director, and a stage actor. The latter kind of training, as one might expect, engenders a strong ego, for acting is a risky business and one must have the confidence to perform often exceedingly strange characters while also challenging and persuading audiences that are sometimes unwilling to suspend their disbeliefs. How does this connect to racquetball? Racquetball games are where I find the antidote for when my strong ego becomes too strong. Regular losses on the racquetball court, which I have enjoyed (re: suffered from) frequently, help keep my mental well-being in balance. My competitors have never been obnoxious in their triumphs, which would cause my dramatic ire to rise, so I have walked away from the games mentally better for them, more in-touch, as it were, with the healthy humility that all humans should possess.

Of course, sometimes I have won. However, I have discovered that the won/loss record, so important to me in my youthful experiences with school-sponsored sports, does not matter much anymore. What matters are the healthy consequences of the exercise, and the friendships forged from the adventures on the court.

I have always been somewhat athletic, a consequence of my youth, as I was brought up in a house that saw athletic endeavour as a requirement! My father was a high school track and field/cross-country coach, so an oft-repeated mantra for my brothers and me was "you've got to be lean and mean," the "mean" referring to a take-no-prisoners competitive drive that gave one an edge in races and events where the place won was vital.

Now, my running days are limited. I still jog/run certain mornings to cross-train, but it is a lonely endeavour, so a few years ago I sought another competitive outlet, and my quest eventually led me to the racquetball courts at this university. I was quickly schooled by other faculty players about the proper attire and scoring system, and the games began! I try to play as many as three times a week, when my directing schedule allows it, and it has been a most enjoyable athletic pursuit. I sweat as much playing a racquetball game as I ever did running track, though I used to win more races than I've won racquetball games.

Yet, as I mentioned, the winning is not the issue as much as other benefits. I would say that a few of my better friends on the faculty are my fellow racquetball players, namely P3, P5, P1, P2, and P6. I have learned much about how the university works just by listening to the conversations of these players and others who work in other colleges than I do, or in administration of the university. The enjoyment of the games is largely due to the banter and camaraderie that exists between the players, which offsets the double-digit losses I have incurred.

The administration of any educational institution would do well to consider the power that collegial exercise such as racquetball has to build strong relationships between faculty that can transcend the courts and benefit the university as a whole. 
In brief, racquetball is good for the university. Exercise helps keep us stress-free and better able to concentrate. Playing the games forges friendships among the faculty. Plus, let's not forget the lessons in humility that playing can offer the even the most egotistical actor among us!

P5

When I took a job at this university 10 years ago, I quickly searched for exercise facilities or an institutionally driven wellness program. I found my new employer had recently implemented a wellness program. A few faculty members and some staff workers routinely walked as part of their exercise regimen, others used the swimming pool, and others frequented the weight room. I wasn't particularly interested in any of those activities, but I was certainly interested in engaging in some kind of exercise routine.

One day I ventured into the racquetball courts and met a couple of senior faculty members who made a terrific first impression. One told me he had been playing for over 20 years, the other more than 15 . One of them, a fellow named P1, asked me, "Are you interested in playing with us? We come to the courts two-to-three times per week." My quick response was direct, "I'll work it into my schedule," I said. The two professors, both of whom were in their late 50 s or early 60 s, looked very fit and very healthy. What impressed me most, however, was when P1 said that the reason he was healthy was because he had made exercise into a priority in his life. "It has to become a way of life for you," he said.

That day they became my workout partners, and more than seven years later, we have added another six or seven partners who exercise regularly, and who are among the healthiest faculty and staff members at the university. P1 captured the essence of our wellness program when he recently wrote to the university vice president whose job is to evaluate wellness activity by saying that our exercise program has "increased work productivity, and the benefits go way beyond costs in terms of improving the quality of work-life and enjoyment."

My exercise routine, which is primarily through playing racquetball, consists of playing three times per week, for a total of about five intense hours of aerobic exercise on the courts. I typically play 10-15 games per week, and keep an exercise schedule that has been steady since I arrived at the campus. I couldn't do this without the commitment from my colleagues, because racquetball is a sport that requires committed partners. We plan our exercise schedules around our teaching, research, and service responsibilities, and coordinate playing times so that everyone gets the opportunity to exercise amply.

The camaraderie and relationships I have built with my exercise friends has proved invaluable for me first as a junior faculty member working toward tenure, and now as an associate professor looking to earn full professorship. I have found my partners as essential for exercise purposes, but they have been equally helpful as mentors who have helped me navigate parts of academic and institutional life. Without question, I have built strong personal and professional relationships with my workout partners, but as importantly, they have taught me the critical importance of committing oneself to an exercise program, as part of how one becomes a healthy and productive member of the faculty.

In short, my exercise partners seldom get sick, and neither do I. In fact, during my seven-tenure, I have yet to miss a day of work because of illness.

P6

I like to play racquetball for many reasons; it is fun, it helps me to stay in shape, I enjoy the competitive nature of it, but mainly because it helps me relieve stress.

I have been playing racquetball since 2002. I remember the first time I played. I had been working very hard for weeks preparing to present my Ph.D. qualifying exams at the university where I completed my degree. I have always been a person who likes to set new goals for myself and I push myself to the limit to achieve them. But while preparing for qualifying exams, I wondered for the first time in my life if I had set up the bar too high. My reality at the time was that I was a foreign student who barely spoke English, a second language that I learned relatively late in my life, at the age of 27. So there I was, having to give a presentation of my research ideas to a very smart group of people, among them faculty and some of my classmates (all geeks).

So, I went to the racquetball courts. I checked out a racquet and challenged the first player that I found there playing. I do not remember the scores of the games, most likely I lost all of them, but I do remember that I really enjoyed it. I had a lot of fun, and after the games, I felt relaxed, and instead of feeling tired I felt with a lot of energy and with a very high level of confidence. After that I thought differently. I thought I'd be giving a talk on a topic in which I was the expert, and at that moment I realized the qualifying exams couldn't be too hard to pass. Then, and now more so, I believe the exercise I got playing racquetball had a direct impact on how I successfully managed the process of passing the qualifying exams.

It is well known that exercise is a great way to relieve stress. Without question, it helps one think more clearly. Racquetball has helped keep me in good shape, physically and mentally, as well as to succeed professionally. One of the first things I did when I arrived at this university as a faculty member in 2004 was to search for racquetball facilities and people willing to play. Lucky for me, this place offers great racquetball facilities, and I have not only found a group of racquetball players who are very competitive, but also I have found in them good friends and excellent colleagues too.

In addition to playing racquetball on a regular basis, I also organized the first faculty/staff racquetball social in 2009, and I helped to organize the first Ironman Racquetball Shootout 2010 tournament, an event where we hosted over 50 players who registered in divisions ranging from amateurs to professional. 